\title{
Trends in gonococcal resistance to antibiotics in Rotterdam, the Netherlands, 1975-86
}

\author{
J H T WAGENVOORT,* J H VAN RIJSOORT-VOS, ${ }^{*}$ J A J W KLUIJTMANS, * \\ M J KIESKAMP,* E STOLZ, $†$ M F MICHEL,* \\ From the departments of *Clinical Microbiology and †Dermatovenereology, University Hospital Dijkzigt, \\ Rotterdam, the Netherlands
}

SUMMARY The incidence of resistance of Neisseria gonorrhoeae to penicillin and tetracycline was periodically monitored during 1975-86. The incidence of resistance to penicillin (minimum inhibitory concentration (MIC) of more than $1.28 \mathrm{mg} / \mathrm{l}$ ) of non-PPNG strains remained low (less than $2.5 \%$ ). The incidence of penicillinase producing $N$ gonorrhoeae (PPNG) strains decreased after a peak of $14 \%$ in 1982 to a mean of $8 \%$ in more recent years. After a gradual increase, the incidence of tetracycline resistant (MIC of more than $1.28 \mathrm{mg} / \mathrm{l}$ ) strains has remained stable at around $20 \%$ during the past five years. This indicates that a continuing increase in incidence of resistance was not observed in this outpatient clinic.

Past decades have shown an increasing incidence of resistance of Neisseria gonorrhoeae to antibiotics. This included the emergence of penicillinase producing $N$ gonorrhoeae (PPNG) strains as well as chromosomally or plasmid mediated resistance to penicillin and tetracycline. ${ }^{1-3}$ The trend of changing patterns of resistance prompted us to monitor its development. Since 1975 we have periodically surveyed the sensitivity to penicillin and tetracycline of $N$ gonorrhoeae strains obtained from patients attending the outpatient clinic of venereology.

We report here our findings regarding the in vitro sensitivity of these strains of $N$ gonorrhoeae.

\section{Patients, materials, and methods}

We cultured strains of $N$ gonorrhoeae from patients (civilians and sailors) attending the venereology outpatient clinic of this hospital. These strains were isolated and identified according to standard procedures. $^{4}$

For this investigation we collected consecutively isolated but independent $N$ gonorrhoeae strains for two months at the beginning of each year from 1975

Address for reprints: Dr JHT Wagenvoort, Department of Clinical Microbilogy, University Hospital Dijkzigt, Dr Molewaterplein 40, 3015 GD Rotterdam, the Netherlands

Accepted for publication 5 November 1986 to 1986 . The number of strains tested in each two month period varied from 139 to 273 . Minimum inhibitory concentrations (MICs) of penicillin and tetracycline were measured by the standard agar dilution method on a gonococcal agar medium, as described previously. ${ }^{4}$ Assays were performed with a bacterial inoculum of $10^{4}$ colony forming units (cfu) per spot, using twofold dilutions of antibiotics ranging between $5.12 \mathrm{mg} / 1$ and $0.005 \mathrm{mg} / \mathrm{l}$. The strains were classified as being sensitive or resistant according to their MICs. Resistance was defined by an MIC of more than $1.28 \mathrm{mg} / \mathrm{l}$. All strains were tested for $\beta$ lactamase production by the chromogenic cephalosporin test (Nitrocephin) to detect PPNG strains.

\section{Results}

The table shows the sensitivity pattern of the $N$ gonorrhoeae strains isolated during the periods monitored. The percentage of non-PPNG strains with MICs of penicillin of more than $1.28 \mathrm{mg} / \mathrm{l}$ was less than $2.5 \%$ and did not alter appreciably during these years. The percentage of strains with MICs of tetracycline of more than $1.28 \mathrm{mg} / 1$ increased substantially from less than $3 \%$ in $1975-79$ to $36 \%$ in 1982 . The mean percentage in $1982-86$ was $21 \%$.

The percentages of PPNG strains increased from $2 \%$ in $1976^{5}$ to a maximum of $14 \%$ in 1982 . After 1982 the mean percentage decreased to $8 \%$. The mean percentage in the period $1979-86$ was $7 \%$. 
Table Range of resistance* of Neisseria gonorrhoeae to penicillin and tetracycline in Rotterdam, first two months of 1975-86

\begin{tabular}{|c|c|c|c|c|}
\hline \multirow[b]{2}{*}{ Year } & \multirow[b]{2}{*}{ No } & \multicolumn{2}{|c|}{$\begin{array}{l}\text { No }(\%) \text { non-PPNG strains } \\
\text { resistant* to: }\end{array}$} & \multirow{2}{*}{$\begin{array}{l}\text { No }(\%) \\
P P N G \\
\text { strains }\end{array}$} \\
\hline & & Penicillin & Tetracycline & \\
\hline $\begin{array}{l}1975 \\
1976 \\
1977 \\
1978 \\
1979 \\
1980 \\
1981 \\
1982 \\
1983 \\
1984 \\
1985 \\
1986\end{array}$ & $\begin{array}{l}242 \\
139 \\
262 \\
270 \\
254 \\
258 \\
273 \\
253 \\
269 \\
257 \\
270 \\
246\end{array}$ & $\begin{array}{l}3(1 \cdot 2) \\
0 \\
1(0 \cdot 4) \\
\text { Not tested } \\
1(0 \cdot 4) \\
3(1 \cdot 2) \\
4(1 \cdot 5) \\
5(2 \cdot 0) \\
4(1 \cdot 5) \\
5(2 \cdot 0) \\
2(0 \cdot 7) \\
6(2 \cdot 4)\end{array}$ & $\begin{array}{c}7(2.9) \\
4(2.9) \\
4(1 \cdot 5) \\
\text { Not tested } \\
2(0.8) \\
9(3.5) \\
14(5 \cdot 1) \\
90(35.6) \\
50(18.6) \\
52(20.2) \\
50(18.5) \\
29(11 \cdot 8)\end{array}$ & $\begin{array}{rr}0 & \\
0 & \\
0 & \\
0 & \\
5 & (2 \cdot 0) \\
6 & (2 \cdot 3) \\
24 & (8 \cdot 8) \\
35 & (13 \cdot 8) \\
32 & (11 \cdot 9) \\
12 & (4 \cdot 7) \\
20 & (7 \cdot 4) \\
17 & (6 \cdot 9)\end{array}$ \\
\hline
\end{tabular}

* Resistance defined by minimum inhibitory concentration of $>1.28 \mathrm{mg} / \mathrm{l}$.

\section{Discussion}

Chromosomally mediated resistance of $N$ gonorrhoeae strains is generally defined by an MIC of penicillin of more than $1 \mathrm{mg} / \mathrm{l}^{36}$ This MIC is also considered to define resistance to tetracycline. ${ }^{67}$ Such MICs correlate with increased treatment failure rates with these drugs. ${ }^{8}$ We chose the nearest MIC $(1.28$ $\mathrm{mg} / \mathrm{l})$ as the break point to define resistance. All PPNG strains were regarded as being resistant to penicillin.

PPNG strains were first isolated in this outpatient clinic in $1976,{ }^{5}$ outside the two month period monitored here. The yearly numbers of infections with PPNG strains in 1976, 1977, and 1978 were 3,4 , and 6 respectively, which contributed less than $0.5 \%$ to the total number of strains isolated in these years. This observation indicates that the results of the periods monitored may not always completely reflect the yearly pattern. The percentage of PPNG strains fell from its zenith in 1982 to an average of $7.8 \%$ from 1983 onwards. This trend was also observed in Great Britain. $^{3}$

The incidence of penicillin resistant non-PPNG strains remained low (0-2.4\%) without substantial changes during the study. For tetracycline, however, a sudden unexplained increase in resistance was noted in 1981-82. Thereafter, incidence stabilised at a much higher level than before. High level resistance (MICs of $16-32 \mathrm{mg} / \mathrm{l})$ of $N$ gonorrhoeae to tetracycline was first reported in $1985 .^{7}$ Screening for this level of resistance of the strains tested in 1986 proved negative. Moreover, measurement of MICs of tetracycline against more than 500 other $N$ gonorrhoeae strains, performed during studies of antigonococcal treatment with antibiotics, ${ }^{9}$ showed maximum MICs of tetracycline of $4 \mathrm{mg} / \mathrm{l}$.

We conclude that stabilisation, rather than an increase in the incidence of resistant strains, has been observed in our institute in the past four years. Despite these findings, continued monitoring would seem to be justified to detect any sudden emergence of new forms or changing patterns of incidence of resistance.

We thank Mrs P Jansen for typing the manuscript.

\section{References}

1 Jaffe HW, Bidde JW, Thornsberry C, et al. National gonorrhea therapy monitoring study. In vitro antibiotic susceptibility and its correlation with treatment results. $N$ Engl $J$ Med 1976;294:5-9.

2 Centers for Disease Control. Changing trends in gonococcal antibiotic resistance in the United States, 1983-1984. MMWR 1985;33:11-5SS.

3 Easmon CSF. Gonococcal resistance to antibiotics. J Antimicrob Chemother 1985;16:409-17.

4 Stolz E, Zwart HGF, Michel MF. Sensitivity to ampicillin, penicillin and tetracycline of gonococci in Rotterdam. British Journal of Venereal Diseases 1974;50:202-7.

5 Blog FB, Chang A, dè Koning GAJ, Oranje AP, Stolz E. Penicillinase-producing strains of Neisseria gonorrhoeae isolated in Rotterdam. British Journal of Venereal Diseases 1977; 53:98-100.

6 Rice RJ, Biddle JW, JeanLouis YA, DeWitt WE, Blount JH, Morse SA. Chromosomally mediated resistance in Neisseria gonorrhoeae in the United States: results of surveillance and reporting, 1983-1984. J Infect Dis 1986;153:340-5.

7 Centers for Disease Control. Tetracycline-resistant Neisseria gonorrhoeae-Georgia, Pennsylvania, New Hampshire. MMWR 1985;34:563-70.

8 Guinan ME, Biddle J, Thornsberry C, Reynolds G, Zaidi A, Wiesner $\mathrm{P}$. The national gonorrhea therapy monitoring study. I. Review of treatment results and in-vitro antibiotic susceptibility, 1972-1978. Sex Transm Dis 1979;6:93-102.

9 Stolz E, Tegelberg-Stassen MJA, Van der Willigen AH, et al. Quinolones in the treatment of gonorrhoea and Chlamydia trachomatis infections. Pharm Weekbl [Sci] 1986;8:60-2. 